\title{
Biodiesel production from used frying oil and microalgae: a preliminary study
}

\author{
M. Chamoumi, M. Veillette, N. Faucheux \& M. Heitz \\ Department of Chemical Engineering and Biotechnological Engineering, \\ Faculty of Engineering, Université de Sherbrooke, Canada
}

\begin{abstract}
In order to replace 1st generation biodiesel, used frying oil (UFO) and microalgae lipids (Tetraselmis sp.) were tested as feedstocks for biodiesel production. The following conditions were tested for UFO homogenous alkali transesterification: temperature $-60^{\circ} \mathrm{C}$; methanol to UFO molar ratio $-6: 1$; catalyst (potassium hydroxide) to UFO mass ratio $-1 \%$; reaction time $-10 \mathrm{~min}$. A biodiesel yield of $80 \%$ (g biodiesel/g UFO) was obtained with a fatty acid methyl ester (FAME) content of $87 \%$ (g FAME/g biodiesel). For microalgae lipids homogenous acid transesterification (catalyst: sulphuric acid), a reaction time of $10 \mathrm{~min}$ and a temperature of $68^{\circ} \mathrm{C}$ led to a biodiesel yield of $50 \%$ (g biodiesel/g lipid). This study showed the potential of Tetraselmis sp. microalgae as feedstock for biodiesel production even if UFO resulted in a higher biodiesel yield.

Keywords: used frying oil (UFO), microalgae, transesterification, biodiesel, Tetraselmis sp.
\end{abstract}

\section{Introduction}

As a consequence of the increase of oil consumption, the disappearance of non-renewable sources of energy will create a problem of fuel depletion. As an example, the Energy Information Administration (EIA) estimates the oil stock to 1690 billion oil barrels [1], which would correspond to a complete depletion in 2050 [2]. This could be attributable to the increase of emerging countries industrialization such as China (second oil consumer with 10.3 million barrels per day) [3]. Consequently, in 2012, the world oil consumption was 90 million barrels per day [1] and it will reach 107 million barrels per day in 2030 (80\% of this increase would be attributable to the transportation sector) [4]. 
In order to solve this problem, some countries have the objective to increase their biofuels (bioethanol, biodiesel, etc.) production. As an example, the United States of America will increase their biofuels production to 160 billion L by 2022 [5]. Consequently, this higher amount biofuel production could lead to several difficulties such as the availability of raw materials required to produce biodiesel and could increase the food prices. In parallel, high volumes of used frying oil (UFO) are produced from cooking industry, which represents an interesting avenue to produce biodiesel instead of using virgin oil. In the United States of America, 11.4 billion L of waste oil are produced annually by hotels and restaurants [6], which could be a part to fulfill the need in raw material for biodiesel production. Microalgae are also interesting to produce biodiesel, as these photosynthetic microorganisms can consume carbon dioxide $\left(\mathrm{CO}_{2}\right)$ and synthesize a biomass with lipid contents up to $75 \%$ dry weight [7]. Moreover, as this biomass is cultivated in water, this type of raw material for biodiesel production does not compete with food crops in opposition to oleaginous plants $[8,9]$. Moreover, microalgae have growth rates and culture yields 30 times higher than other oleaginous species [7].

Fatty acid methyl esters (FAME) are produced by a transesterification reaction between 1 molecule of triglyceride, contained in oleaginous seeds or in microalgae, and 3 molecules of an alcohol (usually methanol because it is cheaper) in presence of a homogenous or heterogeneous catalyst (acid, alkali or enzymatic). Homogenous alkali transesterfication is often preferred for $1^{\text {st }}$ generation biodiesel production because it is faster than homogenous acid reaction [10].

On the other hand, for microalgae lipids, alkali homogenous transesterification is less effective than homogenous acid transesterification. As an example, using heterotrophic microalgae, Nagle and Lemke [11] showed that the FAME yield obtained by homogenous acid transesterification (using hydrochloric acid $(\mathrm{HCl})$ ) at $70^{\circ} \mathrm{C}$ for 30 min was 50 times higher than homogenous alkali transesterification (using sodium hydroxide $(\mathrm{NaOH})$ ) by employing the same operating conditions (68 vs. 1.3\% g FAME/g lipid).

Among the microalgae, Tetraselmis $s p$. is a green phytoplankton [12] extensively studied for aquaculture [13], pharmacological purposes (due to antioxidant content) [14, 15] and to evaluate the marine ecotoxicity [16]. Moreover, this microalgae could be interesting for biodiesel production because it lipids content can reach up to $23 \%$ (g lipid/g dry biomass) [9].

The main objective of this project was therefore to evaluate the potential of using UFO and microalgae lipids as raw materials to produce biodiesel.

\section{Materials and methods}

\subsection{Feedstock}

Hexane, methanol and chloroform ACS grade solvents and potassium hydroxide $(\mathrm{KOH})$ were purchased from Fischer Scientific inc. (Whitby, On., Canada), while sulfuric acid $\left(\mathrm{H}_{2} \mathrm{SO}_{4}\right)(95-98 \mathrm{wt} \%)$ and anhydrous sodium sulfate $\left(\mathrm{Na}_{2} \mathrm{SO}_{4}\right)(99 \mathrm{wt} \%)$ were provided by Anachemia (Lachine, Qc, Canada). 
Raw UFO was supplied by the Université de Sherbrooke cafeteria (Université de Sherbrooke, Sherbrooke, Canada). In order to remove solids, the raw UFO was centrifugated at $4000 \mathrm{rpm}$ for $30 \mathrm{~min}$ at room temperature. The upper phase was filtered under vacuum and dried overnight at $105^{\circ} \mathrm{C}$ in order to remove water traces.

Wet microalgae (Tetraselmis sp.) were supplied by Aquamerik Inc. (Saint-Nicolas, Qc, Canada). The microalgae size ranged from 10 to 12 micrometers with a solid content of $18 \mathrm{wt} \%$ (supplier data).

\subsection{Microalgae lipid extraction}

Frozen microalgae were lyophilized for $24 \mathrm{~h}$ at $-50^{\circ} \mathrm{C}$ under reduced pressure $(<100$ mbar) using a Virtis freeze dryer (model 24D824, Gardiner, New York, USA) for 1-2 days. Microalgae lipids were extracted with a 2-steps extraction using a Soxhlet apparatus: $1^{\text {st }}$ and $2^{\text {nd }}$ step (both for $2 \mathrm{~h}$ ) used hexane and chloroform, respectively. The organic solvents were evaporated under vacuum $\left(65^{\circ} \mathrm{C}\right)$ and the lipids were weighted. Following both extractions, the lipid yield obtained was $12.4 \pm 0.4 \%$ (g lipid/g dry biomass) with no significant effect of the chloroform extraction. This lipid yield was slightly lower than that mentioned by Chisti [9] (15 to 23\% g lipid/g dry weight) using the microalgae Tetraselmis $s p$.

\subsection{Transesterification and biodiesel separation}

\subsubsection{Used frying oil}

Into a $100 \mathrm{~mL}$ 3-necks round bottom flask equipped with a reflux column, $12.5 \mathrm{~g}$ of UFO were heated at the required temperature with magnetic stirring. Then, $2.9 \mathrm{~g}$ of a $4 \mathrm{wt} \% \mathrm{KOH}-$ methanol solution were added to the UFO (corresponding to a methanol to UFO molar ratio of $6: 1$ and a $\mathrm{KOH}$ to UFO ratio of $1 \mathrm{wt} \%)$. At the end of reaction time, the flask was cooled down and the product was transferred into a separation funnel. Then, glycerol (dark brown bottom phase) was recovered and distilled water was added in order to neutralize the organic phase (biodiesel) and to wash methanol. The blend was allowed to settle for $20 \mathrm{~h}$, the biodiesel was recovered and dried using $\mathrm{Na}_{2} \mathrm{SO}_{4}$. Then, methanol was evaporated at $65^{\circ} \mathrm{C}$ under vacuum.

\subsubsection{Microalgae lipids}

Into a $15 \mathrm{~mL}$ round bottom flask equipped with a reflux column, between 0.2 and $0.3 \mathrm{~g}$ of the extracted lipids from Tetraselmis $s p$. were transesterified using $4 \mathrm{~mL}$ of a $4 \%(\mathrm{v} / \mathrm{v}) \mathrm{H}_{2} \mathrm{SO}_{4} /$ methanol solution and $1 \mathrm{~mL}$ hexane. The blend was heated (water bath) to 3 temperatures $\left(24,40\right.$ and $\left.68^{\circ} \mathrm{C}\right)$ for 4 reaction times $(10,30,60$ and $180 \mathrm{~min})$. The blend was cooled down and transferred into a separation funnel with $20 \mathrm{~mL}$ hexane. The organic phase (biodiesel and hexane) was recovered and washed with $20 \mathrm{~mL}$ distilled water. The blend was allowed to settle overnight prior to the separation. Then, $\mathrm{Na}_{2} \mathrm{SO}_{4}$ was used to dry the organic phase (biodiesel and hexane) and the organic solvent (hexane) was evaporated at $65^{\circ} \mathrm{C}$ under vacuum. 


\subsection{Biodiesel analysis}

\subsubsection{Physicochemical analysis}

Biodiesel viscosity was measured at $40^{\circ} \mathrm{C}$ using a Brookfield DV-III Ultra rheological instrument (Brookfield Engineering Laboratories, Inc., Middleboro, Massachusetts, USA).

\subsubsection{Gas chromatography}

Qualitative biodiesel FAME composition was analysed using a Varian-3800 gas chromatograph equipped with a mass spectrometer (Varian Inc, Canada). One $\mu \mathrm{L}$ of a biodiesel-hexane solution was injected in a DB-225 cyanopropylphenyl-dimethylpolysiloxane $(30 \mathrm{~m}$ x $0.25 \mathrm{~mm}$ I.D., $0.25 \mu \mathrm{m}$ film thickness) capillary column (Agilent, Canada). The column oven was heated at $70^{\circ} \mathrm{C}$ for $1 \mathrm{~min}$, from 70 to $180^{\circ} \mathrm{C}$ at $20^{\circ} \mathrm{C} / \mathrm{min}$, from 180 to $220^{\circ} \mathrm{C}$ at $3^{\circ} \mathrm{C} / \mathrm{min}$ and maintained at $220^{\circ} \mathrm{C}$ for $15 \mathrm{~min}$. Helium (Praxair, Canada) was used as a gas carrier at a flow rate of $2.2 \mathrm{~mL} / \mathrm{min}$ (100:1 split ratio).

A commercial standard of 37 FAMEs (Supelco, 18919-1AMP, USA) was used.

\section{Results and discussion}

\subsection{Used frying oil transesterification}

Figure 1 presents the biodiesel yield and the FAME content as a function of the reaction temperature for UFO transesterification. For both reaction times (10 and $60 \mathrm{~min}$ ), the reaction temperature had a limited effect of FAME content, as the FAME contents varied respectively from 83.4 to $87.3 \%$ (g FAME/g biodiesel) and from 91.6 to 93.6 (g FAME/g biodiesel), for 10 and 60 min reaction time, respectively. The reaction temperature (for a reaction time of $60 \mathrm{~min}$ ) has also a limited effect on the biodiesel yield with values ranging from 79.4 to $80.5 \%$ (g biodiesel/g UFO). For a $10 \mathrm{~min}$ reaction time, an increase of the reaction temperature from 24 to $60^{\circ} \mathrm{C}$ increased biodiesel yield from 64.1 to $81.0 \%$ (g biodiesel/g UFO). Over a temperature of $60^{\circ} \mathrm{C}$, the biodiesel yield remained relatively stable at about $81 \%$ (g FAME/g UFO).

The fact that the temperature has no great effect on the FAME content means that the reaction of transesterification using $\mathrm{KOH}$ as a catalyst is a fast reaction. Despite the fact that biodiesel yields were similar for reaction times of 10 and $60 \mathrm{~min}$ at a temperature superior or equal to $60^{\circ} \mathrm{C}$, a reaction time of $60 \mathrm{~min}$ is preferable in order to obtain a higher FAME content. In fact, a lower FAME content would mean that the content of unconverted UFO was higher, creating problems during the biodiesel combustion [17] and increasing the cost linked to the biodiesel purification. Furthermore, the values of viscosity obtained were significantly lower for a reaction time of $60 \mathrm{~min}\left(3.47 \pm 0.50 \mathrm{~mm}^{2} / \mathrm{s}\right)$ than for a reaction time of $10 \mathrm{~min}\left(5.00 \pm 0.77 \mathrm{~mm}^{2} / \mathrm{s}\right)$ (data not shown). It is to be noted that most of vegetable oil transesterification is performed at a temperature of $60^{\circ} \mathrm{C}$ for at least $60 \mathrm{~min}$ reaction time $[18,19]$. 


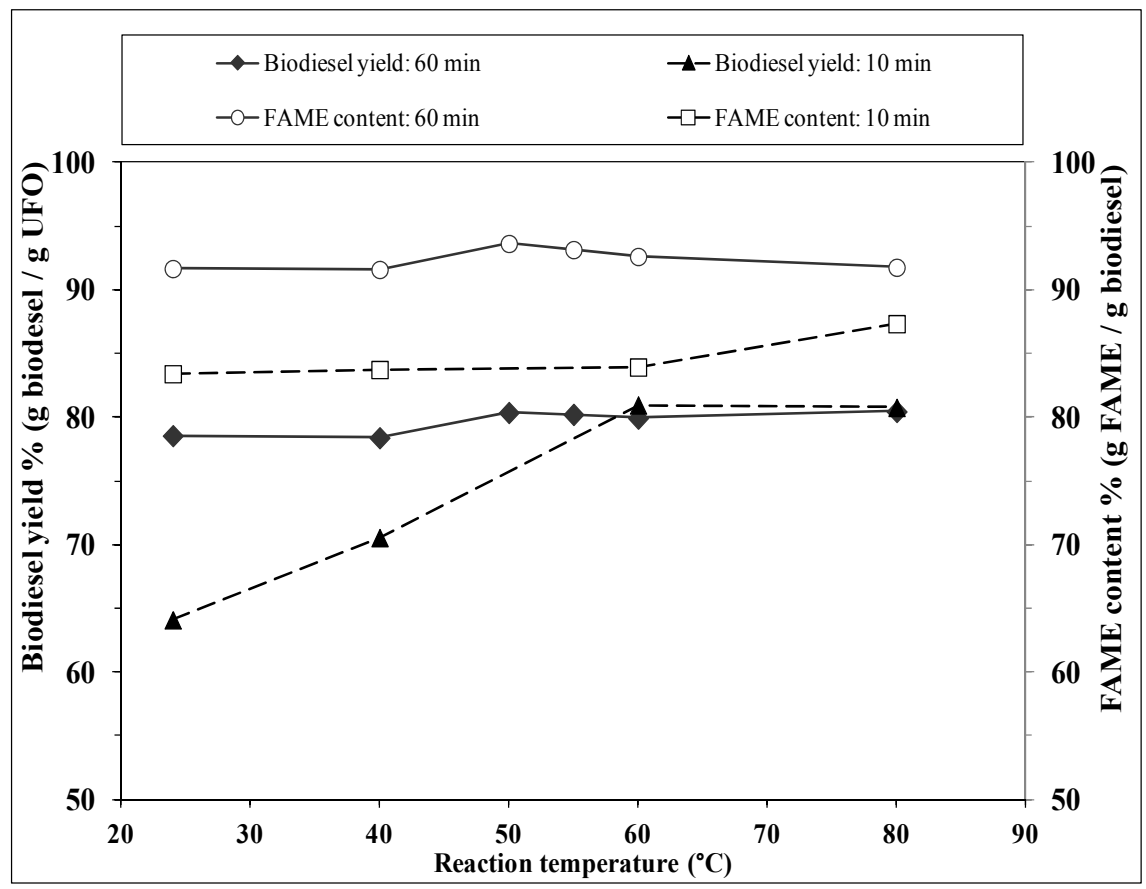

Figure 1: $\quad$ Biodiesel yield and FAME content for UFO transesterification for $10 \mathrm{~min}$ and $60 \mathrm{~min}$ reaction times as a function of reaction temperature (methanol to UFO molar ratio: 6:1; catalyst $(\mathrm{KOH})$ concentration: $1 \mathrm{wt} \%$ relative to $\mathrm{UFO})$.

\subsection{Microalgae lipids transesterification}

Figure 2 presents the biodiesel yield as a function of the temperature for microalgae lipid transesterification. For temperatures ranging from 24 to $68^{\circ} \mathrm{C}$, the biodiesel yield increased from 31.1 to $50.2 \%$ (g biodiesel $/ \mathrm{g}$ lipid) and from 41.0 to $51.0 \%$ (g biodiesel $/ \mathrm{g}$ lipid) for respective reaction times of 10 and $60 \mathrm{~min}$.

As seen in Figure 2, in opposition to homogenous alkali catalysis (Figure 1), temperature had a more important effect on the biodiesel yield, as homogenous acid catalysis is 4000 times slower than homogenous alkali catalysis [10]. Moreover, a temperature of $24^{\circ} \mathrm{C}$ and a reaction time of $10 \mathrm{~min}$ resulted in a lower biodiesel yield (-24\%) compared to a reaction time of $60 \mathrm{~min}$. The results indicate that the conversion of lipids contained in the microalgae is influenced by the reaction temperature [20]. 


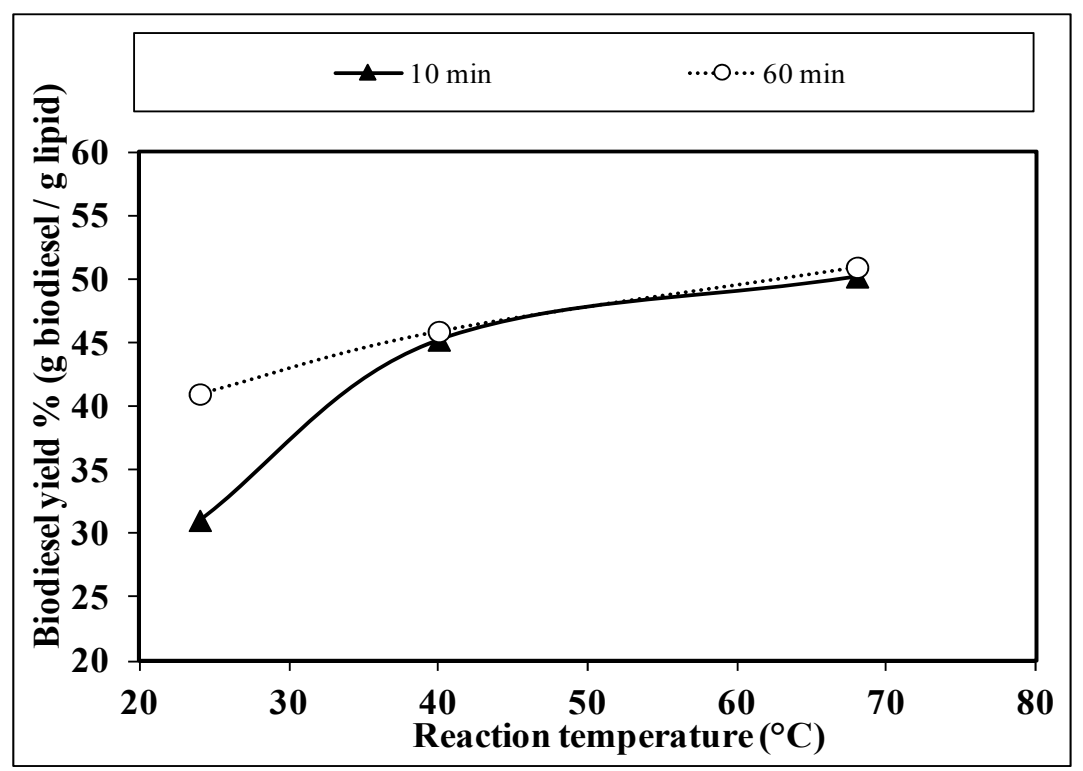

Figure 2: $\quad$ Biodiesel yield as a function of the reaction temperature for microalgae lipid transesterification for 10 and 60 min reaction times (methanol to lipid ratio: $13 \mathrm{~mL} / \mathrm{g}$; catalyst concentration: $4 \% \mathrm{v} / \mathrm{v} \mathrm{H} 2 \mathrm{SO} 4 /$ methanol solution).

\subsection{Comparison of biodiesel FAME compositions}

Figure 3 presents the chromatographic area for each FAME issued from UFO and microalgae biodiesel. As seen in Figure 3, the UFO biodiesel presents a very different composition compared to the microalgae biodiesel. The first difference is the number of different FAMEs: Microalgae biodiesel contained 14 FAMEs (from $\mathrm{C} 14$ to $\mathrm{C} 20$ ) while UFO biodiesel contained only 6 FAME (from C16 toC18). For UFO, the main compounds were methyl elaidate (C18:1-trans, 63.9\%), methyl linoleate (C18:2, 18.7\%) and methyl linoate $(\mathrm{C} 18: 3,7.9 \%)$. For microalgae, the main components were methyl palmitate, (C16:0, 20.1\%) methyl palmitoleate (C16:1, 17.3\%) and methyl 4, 7, 10, 13 hexadecatetraenoate $(\mathrm{C} 16: 4,15.0 \%)$.

One of the usual problems with microalgae lipids is the presence of polyunsaturated FAMEs ( $>3$ double bounds) which could create problems of oxidation during biodiesel storage [21, 22]. In case of Tetraselmis sp. microalgae, the polyunsaturated FAMEs content (such as C16:4 and C18:4) of the biodiesel (based on chromatographic relative area) was lower than $29 \%$.

Based on these results, UFO biodiesel would be more suitable for biodiesel production than microalgae lipids because the latter would require further purification steps but polyunsaturated lipids contained in Tetraselmis sp. microalgae lipids could have interesting properties for other purposes than biodiesel production [23]. 


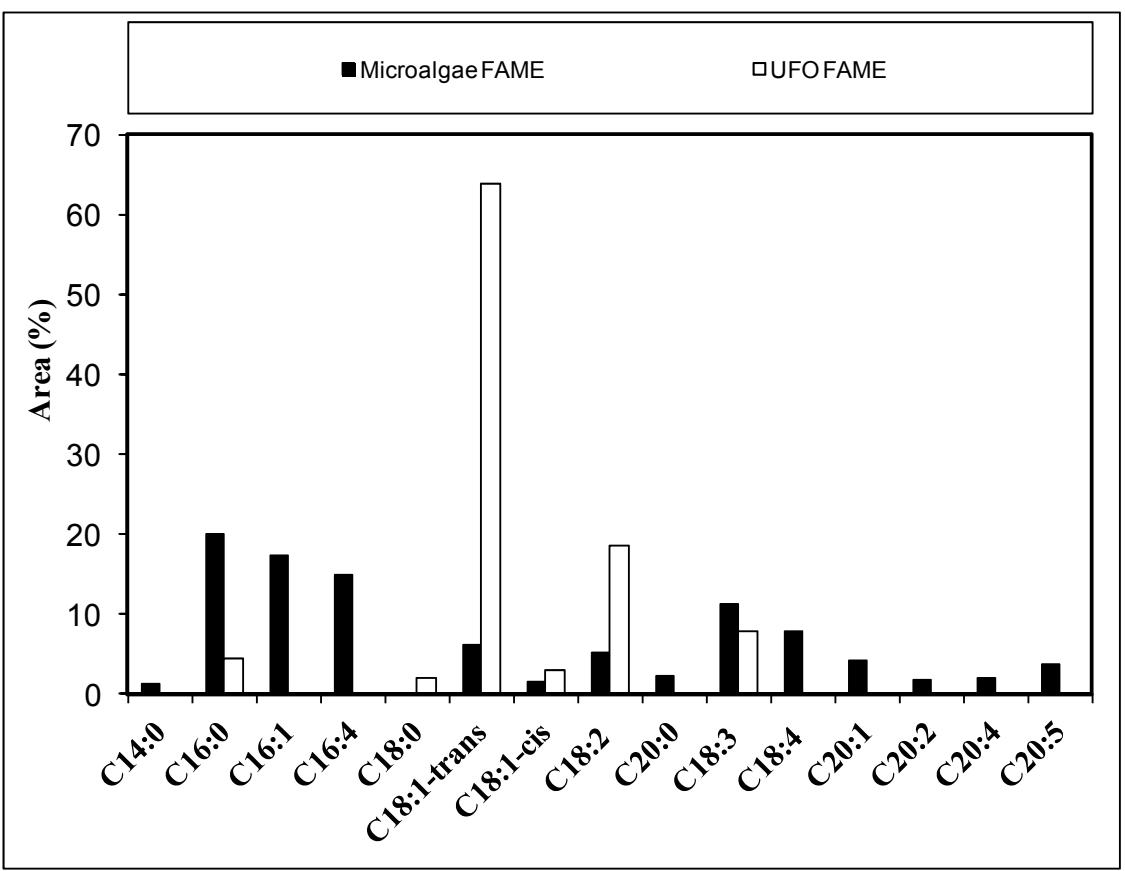

Figure 3: Qualitative FAME composition (chromatographic relative area) for UFO transesterification (temperature: $60^{\circ} \mathrm{C}$; methanol to UFO molar ratio: $6: 1 ; \mathrm{KOH}$ to $\mathrm{UFO}$ mass ratio: $1 \%$ ) and microalgae lipids transesterification (temperature: $68^{\circ} \mathrm{C} ; 4 \% \mathrm{v} / \mathrm{v}$ $\mathrm{H} 2 \mathrm{SO} 4 /$ methanol solution; methanol to lipid ratio: $13 \mathrm{~mL} / \mathrm{g}$ ) for a reaction time of $60 \mathrm{~min}$.

\section{Conclusion}

In order to reduce oil consumption, new feedstocks should be considered to produce biofuels such as biodiesel. The main objective of this study was to test UFO and microalgae lipids (Tetraselmis sp.) as feedstocks for biodiesel production. For UFO homogenous alkali transesterification $(\mathrm{KOH})$ at a temperature of $60^{\circ} \mathrm{C}$ (methanol to UFO ratio: 6:1 and catalyst $(\mathrm{KOH})$ to UFO ratio: $1 \mathrm{wt} \%$ ), the reaction time had no effect on the FAME contents (91.6-93.6 \% g FAME/g biodiesel) and the biodiesel yields (79.4 to 80.5\% (g biodiesel/g UFO)) which indicates that the reaction of transesterification (in these operating conditions) is not sensitive to the temperature.

For microalgae lipid homogenous acid transesterification $\left(\mathrm{H}_{2} \mathrm{SO}_{4}\right)$, for a reaction time of $60 \mathrm{~min}$, an increase of the reaction temperature from 24 to $68^{\circ} \mathrm{C}$ seems to have a significant effect on the biodiesel yield with an increase from 41.0 to $51.0 \%$ (g biodiesel/g lipid). These results showed that UFO is adapted to replace $1^{\text {st }}$ generation biodiesel but Tetraselmis $s p$. microalgae biodiesel should be further investigated. 


\section{Acknowledgements}

Michèle Heitz is grateful to le Fond Québécois de la Recherche sur la Nature et les Technologies (FQRNT) for the grant for the research program in partnership contributing to the reduction of greenhouse gases. Marc Veillette wants also to express his gratitude to the National Sciences and Engineering Research Council of Canada (NSERC) for the doctorate scholarship. Thanks also have to be expressed to the department of biology in Université de Sherbrooke for the use of the lyophilisation apparatus.

\section{References}

[1] BP, BP statistical review of world energy BP, 2013, http://www.bp.com/liveassets/bp_internet/globalbp/globalbp_uk_english/r eports_and_publications/statistical_energy_review_2011/STĀGING/local assets/pdf/statistical_review_of_world_energy_full_report_2012.pdf.

[2] Shafiee, S. \& Topal, E., When will fossil fuel reserves be diminished? Energy Policy, 37, pp. 181-189, 2009.

[3] US Energy Information Administration, 20012 world oil consumption, 2013b, http://www.eia.gov/countries/index.cfm?view=consumption.

[4] Energy Information Administration, Energy outlook 2009, 2009, http://www.eia.doe.gov/oiaf/ieo/pdf/0484(2009).pdf.

[5] Banerjee, N., US to reduce oil imports by a third by 2021, Obama says. Los Angeles Times, 2011, http://articles.latimes.com/2011/mar/31/ nation/la-na-obama-energy-20110331/2.

[6] United States Environmental Protection Agency, Learn About biodiesel, 2014, http://www.epa.gov/region9/waste/biodiesel/questions.html.

[7] Deng, X., Li, Y. \& Fei, X., Microalgae: A promising feedstock for biodiesel. African Journal of Microbiology Research, 3(13), pp. 1008-1014, 2009.

[8] Goldemberg, J. \& Guardabassi, P., Are biofuels a feasible option? Energy Policy, 37(1), pp. 10-14, 2009.

[9] Chisti, Y., Biodiesel from microalgae. Biotechnology Advances, 25(3), pp. 294-306, 2007.

[10] Freedman, B., Butterfield, R.O. \& Pryde, E.H., Transesterification kinetics of soybean oil. Journal of American Oil Chemical Society, 63, pp. 1375-1380, 1986.

[11] Nagle, N. \& Lemke, P., Production of methyl-ester fuel from microalgae. Applied Biochemistry and Biotechnology, 24(24-25), pp. 355-361, 1990.

[12] Throndsen, J., The planktonic marine flagellates Identifying Marine Phytoplankton, ed. C. R. Tomas, Academic Press: San Diego, Ca, USA, pp. 651-664, 1997.

[13] Tawfiq, A.S., Al-Musallam, L., Al-Shimmari, J. \& Dias, P., Optimum production conditions for different high-quality marine algae. Hydrobiologia, 403, pp. 97-107, 1999. 
[14] Laguna, M.R., Villar, R., Cadavid, I. \& Calleja, J.M., Effects of extracts of Tetraselmis suecica and Isochrysis galbana on the central nervous system. Planta Medica, 59, pp. 207-214, 1993.

[15] Kim, S.K., Byun, H.G., Park, P.J. \& Adachi, K., Purification and structure of antioxidative substance derived from Tetraselmis suecica. Journal of Korean Fisheries Society, 35, pp. 155-161, 2002.

[16] Park, G.S., Lee, S.H., Lee, S.M., Yoon, S.J. \& Park, S.Y., Phytoplankton as standard test species for marine ecotoxicological evaluation. Journal of Environmental Sciences, 14, pp. 1129-1139, 2005.

[17] Basha, S.A., Gopal, K.R. \& Jebaraj, S., A review on biodiesel production, combustion, emissions and performance. Renewable and Sustainable Energy Reviews, 13(6-7), pp. 1628-1634, 2009.

[18] Lisa, M., Lynen, F., Holcapek, M. \& Sandra, P., Quantitation of triacylglycerols from plant oils using charged aerosol detection with gradient compensation. Journal of Chromatography A, 28, pp. 135-142, 2007.

[19] Jordanov, D.I., Petkov, P.S., Dimitrov, Y.K. \& Ivanov, S.K., Methanol transesterification of different vegetable oils. Petroleum and Coal, 49, pp. 21-23, 2007.

[20] Tesser, R., Casale, L., Verde, D., Di Serio, M. \& Santacesaria, E., Kinetics of free fatty acids esterification: Batch and loop reactor modeling. Chemical Engineering Journal, 154(1-3), pp. 25-33, 2009.

[21] Stansell, G.R., Gray, V.M. \& Sym, S.D., Microalgal fatty acid composition: implications for biodiesel quality. Journal of Applied Phycology, 2011.

[22] Veillette, M., Chamoumi, M., Nikiema, J., Faucheux, N. \& Heitz, M., Production of biodiesel from microalgae Chemical Engineering, ed. Mawaz, Z. \& Naveed, S., Intech: Rijeka, Croatia, pp. 1-24, 2012.

[23] Molina Grima, E., Belarbi, E.H., Acién Fernández, F.G., Robles Medina, A. \& Chisti, Y., Recovery of microalgal biomass and metabolites: process options and economics. Biotechnology Advances, 20(7-8), pp. 491-515, 2003. 